\title{
Striatal Preproenkephalin Gene Expression Is Upregulated in Acute but Not Chronic Parkinsonian Monkeys: Implications for the Contribution of the Indirect Striatopallidal Circuit to Parkinsonian Symptomatology
}

\author{
Jay S. Schneider, Emmanuel Decamp, and Timothy Wade \\ Department of Pathology, Anatomy, and Cell Biology, Thomas Jefferson University, Philadelphia, Pennsylvania 19107
}

This study examined the extent of striatal dopamine (DA) denervation and coincident expression of preproenkephalin (PPE) mRNA in monkeys made parkinsonian by 1-methyl-4-phenyl1,2,3,6-tetrahydropyridine (MPTP) administration. Some animals $(n=4)$ became moderately parkinsonian after receiving large doses of MPTP over short periods of time and were symptomatic for only a short period of time (1-3 months; acute parkinsonian group). Other animals became moderately parkinsonian after receiving either escalating doses of MPTP over long periods (4-6 months; $n=5$ ) or a high dose of MPTP over a short period ( $<1$ month; $n=1$ ) and remained symptomatic for an extended period (>8 months; chronic parkinsonian group). Despite similar symptomatology and similar degrees of striatal

Numerous papers have reported changes in striatal preproenkephalin mRNA levels in animals with nigrostriatal dopaminergic lesions. After 6-hydroxydopamine lesions in rats, levels of enkephalin mRNA and protein were found to be increased in GABA-containing striatopallidal projection neurons that also express dopamine (DA) D2 receptors (Young et al., 1986; Normand et al., 1988; Gerfen et al., 1990). In nonhuman primates, administration of the neurotoxin 1-methyl-4-phenyl1,2,3,6-tetrahydropyridine (MPTP), either systemically or by intracarotid infusion, has resulted in marked increases in preproenkephalin (PPE) gene expression, particularly in the dorsolateral sensorimotor striatal territories (Augood et al., 1989; Asselin et al., 1994; Herrero et al., 1995). These data, as well as findings from a number of other studies (Voorn et al., 1987; Robertson et al., 1990; Sivam and Krause, 1990), support the proposal that DA exerts a tonic inhibitory control, mediated via D2 receptors, over enkephalin-containing striatopallidal output neurons.

Although studies with animal models of Parkinson's disease (PD) have produced very consistent findings in regard to increases in enkephalin gene expression, studies of enkephalin expression in patients with PD have produced conflicting results. When peptide levels have been measured, some studies have found decreased met-enkephalin levels in either the caudate

\footnotetext{
Received March 12, 1999; revised May 7, 1999; accepted May 13, 1999.

This research was supported by National Institutes of Health Grant MS 46539 and by the F. M. Kirby Foundation. We thank Mary G. Smith for her expert histological work.

Correspondence should be addressed to Dr. J. S. Schneider, Department of Pathology, Anatomy, and Cell Biology, Thomas Jefferson University, 1020 Locust Street, 521 JAH, Philadelphia, PA 19107.

Copyright (C) 1999 Society for Neuroscience $\quad 0270-6474 / 99 / 196643-07 \$ 05.00 / 0$
}

DA denervation at the time of their deaths, only acute parkinsonian animals had significantly increased PPE expression in sensorimotor striatal regions. PPE expression in chronic parkinsonian animals was either not changed or significantly decreased in most striatal regions. These findings suggest that the duration and not the extent of striatal DA denervation is a critical factor in modulating changes in striatal PPE expression. Furthermore, these results question the role of increased activity in the enkephalin-containing indirect striatopallidal pathway in the expression of parkinsonian symptoms.

Key words: enkephalin; striatum; parkinsonism; dopamine; monkeys; MPTP

nucleus (Sivam, 1991) or the putamen (Taquet et al., 1983; Llorens-Cortes et al., 1984). Other studies have found no changes in met-enkephalin levels in either the caudate nucleus or the putamen (Fernandez et al., 1992). Although one study (Levy et al., 1995) reported no significant difference in striatal expression of met-enkephalin mRNA in PD patients compared with control subjects, another study (Nisbet et al., 1995) reported a significant increase in PPE mRNA in both the caudate and the putamen in PD cases.

It is difficult to reconcile the results from studies of animal models of PD with results from postmortem studies of PD brains. Both types of studies have a number of difficulties associated with them that cloud the interpretation of their respective findings. The animal studies, all of which have shown a significant increase in met-enkephalin expression, have been conducted on acute models of parkinsonism, i.e., animals with a rapid onset and short duration of DA neuron degeneration and striatal DA depletion. It is difficult to say how the striatal neuropeptide response to this acute DA lesion corresponds to the response of this system to the chronic and slowly progressing degeneration and DA loss seen in PD. A complicating factor in human studies is that expression of neuropeptides may be affected by the long-term use of various anti-Parkinson drug therapies or by the variability of the disease itself [i.e., degree of striatal DA depletion (Sivam, 1991; Fernandez et al., 1992)].

In view of the shortcomings associated with these other studies, the present study was conducted to examine changes in preproenkephalin gene expression in a chronic model of parkinsonism in monkeys. In contrast to most other studies of experimental parkinsonism, the objectives of this study were to examine the similarities and differences between monkeys with acute onset, 
short-duration parkinsonism and animals with acute or chronic onset and long-duration parkinsonism. The results of this study suggest that the duration and not the extent of striatal DA denervation is the most critical factor in modulating striatal PPE expression. The results also question the role of increased activity in the enkephalin-containing indirect striatopallidal pathway as a primary causative factor in the expression of parkinsonian symptoms.

\section{MATERIALS AND METHODS}

Animals. A total of 16 adult male cynomolgus (Macaca fascicularis) monkeys were used in this study. All animals were housed individually in the same room with a $12 \mathrm{hr}$ light/dark cycle. All aspects of this study complied with established federal and institutional guidelines for the care and use of laboratory animals.

Six monkeys received no treatments and were used as normal control animals. Four monkeys were given intravenous or intramuscular injections of MPTP (MPTP-HCl; dissolved in sterile normal saline; Research Biochemicals, Natick, MA) in doses ranging from 0.33 to 0.50 $\mathrm{mg} / \mathrm{kg}$ twice weekly over a period of up to $32 \mathrm{~d}$ to produce moderate to severe parkinsonism (acute symptomatic group). Animals were rated for a variety of behaviors on a rating scale used previously in this laboratory (Schneider et al., 1998). This behavioral/motor rating scale evaluates 19 items associated with motor function and other behaviors such as defense reaction and eating. Scores of 0 are normal; the maximum parkinsonian score that can be achieved is 41 . Ratings were taken twice weekly by an observer blind to the toxin administration paradigm, with the monkey in an observation or testing cage in a quiet room separate from the rest of the monkey colony. These animals comprised the acute symptomatic group and were killed 1-3 months after the last MPTP injection.

Five other monkeys received intravenous injections of MPTP at low doses of $0.05-0.15 \mathrm{mg} / \mathrm{kg}$ two to three times per week over several months (range, 4-7 months). This MPTP administration protocol produces animals that are analogous to early stage PD patients and that have cognitive deficits with mild or no motor deficits. MPTP doses were then increased (up to $0.30-0.50 \mathrm{mg} / \mathrm{kg}$, i.v.; once or twice per week) for an additional 4-6 months until these animals developed stable moderate parkinsonian motor deficits. These animals were killed $\sim 40$ months after the start of MPTP exposure and an average of 8 months $( \pm 2)$ after receiving the last MPTP injection. These monkeys comprise the chronic symptomatic group.

One additional monkey received high-dose MPTP injections $(0.33$ $\mathrm{mg} / \mathrm{kg}$, i.m.; twice weekly) for $\sim 1$ month to produce rapid onset parkinsonism. The MPTP administration protocol was similar to that used in the acute symptomatic group. However, in contrast to the animals in the acute symptomatic group, this animal was killed 17 months after the last injection of MPTP.

All animals were killed by sodium pentobarbital overdose $(150 \mathrm{mg} / \mathrm{kg}$, i.v.), and the brains were removed quickly after cessation of a heartbeat. Each brain was bisected along the midline, and the two hemispheres were immediately frozen by immersion in $-40^{\circ} \mathrm{C}$ isopentane and stored at $-80^{\circ} \mathrm{C}$.

$\left[{ }^{3} H\right] M a z i n d o l$ autoradiography. The extent of striatal DA denervation was assessed by quantitative autoradiography of the binding of $\left[{ }^{3} \mathrm{H}\right]$ mazindol to presynaptic striatal DA uptake sites. Tissue was sectioned at $20 \mu \mathrm{m}$ in a cryostat at $-15^{\circ} \mathrm{C}$, thaw-mounted onto gelatinsubbed slides, dried on a slide warmer, and stored desiccated at $-80^{\circ} \mathrm{C}$. The method for assessing the density of DA uptake sites was essentially the same as reported previously (Rioux et al., 1997). Slides were removed from the freezer, placed on ice, and allowed to thaw for $1 \mathrm{~min}$ before the assay was begun. Slides were then preincubated for $5 \mathrm{~min}$ in Tris buffer $\left(50 \mathrm{~mm}\right.$ Tris base, $300 \mathrm{~mm} \mathrm{NaCl}$, and $5 \mathrm{~mm} \mathrm{KCl}, \mathrm{pH} 7.9$, at $4^{\circ} \mathrm{C}$ ) containing $300 \mathrm{~nm}$ desipramine to block norepinephrine sites. Slides were then incubated for $40 \mathrm{~min}$ at $4^{\circ} \mathrm{C}$ in the same assay buffer containing 15 nM $\left[{ }^{3} \mathrm{H}\right]$ mazindol $(23.5 \mathrm{Ci} / \mathrm{mmol}$; Dupont NEN, Boston, MA) and rinsed twice for $3 \mathrm{~min}$ in ice-cold buffer followed by a $10 \mathrm{sec}$ rinse in double distilled $\mathrm{H}_{2} \mathrm{O}$. Nonspecific binding was determined in alternate sections with the addition of $30 \mu \mathrm{M}$ benztropine and $10 \mu \mathrm{M}$ nomifensine to the incubation buffer. Slides were rapidly dried under a cold air stream for $1 \mathrm{~min}$ and room temperature air for $10 \mathrm{~min}$ and apposed to ${ }^{3} \mathrm{H}$ Hyperfilm (Amersham, Arlington Heights, IL) in sealed cassettes for $21 \mathrm{~d}$ along with calibrated ${ }^{3} \mathrm{H}$-plastic standards (American Radiolabeled
Chemicals, St. Louis, MO). Film was developed in Kodak D-19 developer (Eastman Kodak, Rochester, NY) and fixed.

Preproenkephalin in situ hybridization. Twenty-micrometer-thick sections through the striatum were processed for in situ hybridization histochemistry using a ${ }^{35}$ S-radiolabeled oligonucleotide probe corresponding to amino acids $130-145$ of the human sequence of PPE. Animals representing all treatment groups were always hybridized together in the same run. Seven picomoles of the oligonucleotide probe were incubated at $37^{\circ} \mathrm{C}$ for $60 \mathrm{~min}$ with $5 \mu$ l of $\left[{ }^{35} \mathrm{~S}\right]$ deoxyadenosine $5^{\prime}$-( $\alpha$-thio)triphosphate $(>1000 \mathrm{Ci} / \mathrm{mmol}$; Amersham $), 10 \mu \mathrm{l}$ of TdTtailing buffer, $21.5 \mu \mathrm{l}$ of diethylpyrocarbonate (DEPC)-treated water, 5 $\mu \mathrm{l}$ of $\mathrm{CoCl}_{2}$, and $1.5 \mu \mathrm{l}$ of TdT. The radiolabeled probe was purified at room temperature with two microcentrifuge spins in Phase Lock Gel tubes (5 Prime-3 Prime) containing $50 \mu \mathrm{l}$ of phenol and $50 \mu \mathrm{l}$ of chloroform/isoamylalcohol $(24: 1)$ and then $50 \mu \mathrm{l}$ of chloroform/isoamylalcohol. The purified probe was then precipitated in $4.5 \mathrm{M}$ sodium acetate + yeast tRNA (Sigma, St. Louis, MO) (to avoid loss of oligonucleotide) and ethanol at $-70^{\circ} \mathrm{C}$ overnight. The pellets were redissolved in DEPC-treated water the next day. Tissue sections were brought to room temperature and fixed with $3 \%$ paraformaldehyde for $5 \mathrm{~min}$, followed by washes in DEPC-treated water $(10 \mathrm{sec}), 2 \times \mathrm{SSC}(2 \mathrm{~min}), 0.1 \mathrm{M}$ triethanolamine, $\mathrm{pH} 8.0$, with $0.25 \%$ acetic anhydride $(10 \mathrm{~min})$, and $2 \times \mathrm{SSC}$ (twice for $1 \mathrm{~min}$ ). Sections were then dehydrated in increasing concentrations of ethanol $(70,80$, and $95 \%)$ and air dried. Sections were covered with $60 \mu \mathrm{l}$ of hybridization cocktail [ $900 \mu \mathrm{l}$ of hybridization buffer, $50 \mu$ l of salmon sperm DNA, $24 \mu \mathrm{l}$ of $\left[{ }^{35} \mathrm{~S}\right] \mathrm{PPE}$ probe $\left(1 \times 10^{6}\right.$ counts per section), and $40 \mu \mathrm{l}$ of DTT], coverslipped with parafilm, and allowed to hybridize overnight at $37^{\circ} \mathrm{C}$. After hybridization, the slides were washed at room temperature in $2 \times$ and $1 \times \mathrm{SSC}$ for 1 min each and then four times in $0.5 \times \mathrm{SSC}$ at $55^{\circ} \mathrm{C}$ for $30 \mathrm{~min}$ each. Sections were then dipped in $300 \mathrm{~mm} \mathrm{NH}_{4} \mathrm{OAC}$, dehydrated in increasing concentrations of ethanol, cleared, and dried. The slides were then apposed to $\beta$-Max Hyperfilm for 1 week, developed in Kodak GBX, and fixed with Kodak Rapid Fix.

Data analysis. The striatum was analyzed at three rostrocaudal levels: a rostral level (precommissural) including the caudate, putamen, and nucleus accumbens; a mid level including the caudate, putamen, and external globus pallidus at the level of the decussation of the anterior commissure; and a caudal level (postcommissural) including the body of the caudate, the putamen, and both internal and external globus pallidus segments. $\left[{ }^{3} \mathrm{H}\right]$ mazindol autoradiographs were analyzed using a computer-driven analysis system (BRAIN version 4.0; Drexel University). At each level, at least three sections were analyzed for total binding, and two sections were analyzed for nonspecific binding. Where appropriate, the caudate and putamen were divided into dorsolateral, dorsomedial, ventrolateral, and ventromedial quadrants for analysis. A mean value for each region by level for each case was determined. To assess statistical significance of the quantitative densitometry data, one-way ANOVA was performed to examine group and region interactions. Post hoc pairwise comparisons were performed using Student-NewmanKeuls multiple comparisons test.

Levels of PPE mRNA expression were measured in the striatal regions described above at three different rostrocaudal levels and were quantified by computerized densitometry using NIH Image software (version 1.58). At least five sections per animal per striatal level (rostral, mid, and caudal) were analyzed. A gray scale standard strip was used to generate a calibration curve for optical densities. The person analyzing the films was blind to the treatment group designation for each animal. Optical densities were averaged for each region in each monkey and expressed as the percentage difference from the mean of control animals. Statistical analysis was performed by one-way ANOVA followed by post hoc pairwise comparison with a Student-Newman-Keuls multiple comparisons test.

\section{RESULTS}

\section{Behavior}

All animals were similarly parkinsonian at the end of the study. At the time that animals in the acute symptomatic group were killed, they had a mean behavioral/motor rating of $28 \pm 4$. Animals in the chronic symptomatic group had mean Parkinson ratings of $24 \pm 5$. The monkey with rapid onset but long-duration parkinsonism had a behavioral/motor rating of 32. This animal's anatomical data were no different from that of other monkeys in the chronic symptomatic group. Thus, data from this animal have 
been included in the chronic symptomatic group for statistical analyses.

\section{$\left[{ }^{3} \mathrm{H}\right]$ Mazindol autoradiography}

The regional integrity of the presynaptic DA system was determined by measuring the density of DA uptake sites labeled with $\left[{ }^{3} \mathrm{H}\right]$ mazindol. As described in other studies (Rioux et al., 1997), $\left[{ }^{3} \mathrm{H}\right]$ mazindol binding in normal monkeys varied between the dorsal striatum and ventral striatum, with the ventral striatum showing lower levels of specific binding. At all rostrocaudal levels there were significant group by region effects [rostral level, $F_{(23,79)}=66.12 ; p<0.0001 ;$ mid level, $F_{(23,115)}=84.37 ; p<$ 0.0001 ; and caudal level, $\left.F_{(14,69)}=64.64 ; p<0.0001\right]$. At each rostrocaudal level, pairwise comparisons of $\left[{ }^{3} \mathrm{H}\right]$ mazindol binding in different striatal regions showed significant differences between normal and chronic symptomatic and normal and acute symptomatic animals. However, there were no significant differences in $\left[{ }^{3} \mathrm{H}\right]$ mazindol binding in any striatal region between chronic symptomatic and acute symptomatic animals (Figs. 1, 2).

\section{Preproenkephalin in situ hybridization}

At all rostrocaudal levels there were significant group by region effects on PPE gene expression [rostral level, $F_{(26,117)}=30.29$; $p<0.0001$; mid level, $F_{(23,104)}=8.45 ; p<0.0001$; and caudal level, $\left.F_{(14,65)}=67.44 ; p<0.0001\right]$. In acute symptomatic animals, there were pronounced increases in PPE mRNA levels in the dorsal putamen $(t=-13.42 ; p<0.01$ in the dorsolateral putamen; $t=-10.29 ; p<0.01$ in the dorsomedial putamen) and dorsal caudate $(t=-8.31 ; p<0.01$ in the dorsolateral caudate; $t=-5.35 ; p<0.01$ in the dorsomedial caudate) at the rostral level in comparison with that in normal control animals. The greatest increases were in the dorsolateral regions of both nuclei, with smaller increases that were not statistically significant in the ventral putamen and caudate regions and the nucleus accumbens (Fig. 3).

At the mid level, the regional pattern of PPE mRNA expression was similar to that at the rostral level, but the extent of the increases was somewhat less than that observed more rostrally. In addition to significant increases in PPE gene expression, compared with that in control animals, in the dorsal putamen $(t=$ -7.67; $p<0.01$ in the dorsolateral putamen; $t=-4.06 ; p<0.01$ in the dorsomedial putamen), a significant increase was also seen in the ventrolateral putamen $(t=-3.47 ; p<0.01)$. As at the rostral level, there was increased PPE mRNA expression in the dorsal caudate $(t=-2.91 ; p<0.01$ in the dorsolateral caudate; $t=-2.11 ; p<0.05$ in the dorsomedial caudate) but not in the ventral caudate.

The increase in PPE mRNA levels was greatest at the caudal level, where large increases in signal were not only seen in the dorsal putamen $(t=-13.80 ; p<0.01$ in the dorsolateral putamen; $t=-13.85 ; p<0.01$ in the dorsomedial putamen) but were also observed in the ventral putamen $(t=-8.89 ; p<0.01$ in the ventrolateral putamen; $t=-9.15 ; p<0.01$ in the ventromedial putamen) and the body of the caudate nucleus $(t=-10.73 ; p<$ 0.01) (Fig. 3). At all rostrocaudal levels, increased signal was localized mostly to the sensorimotor striatal territories.

In contrast to what was observed at the rostral level in the dorsal striatum in acute symptomatic animals, there were no statistically significant increases in PPE gene expression compared with that in control animals in either the caudate or putamen in the chronic symptomatic animals. There were however significant decreases from normal levels of PPE mRNA

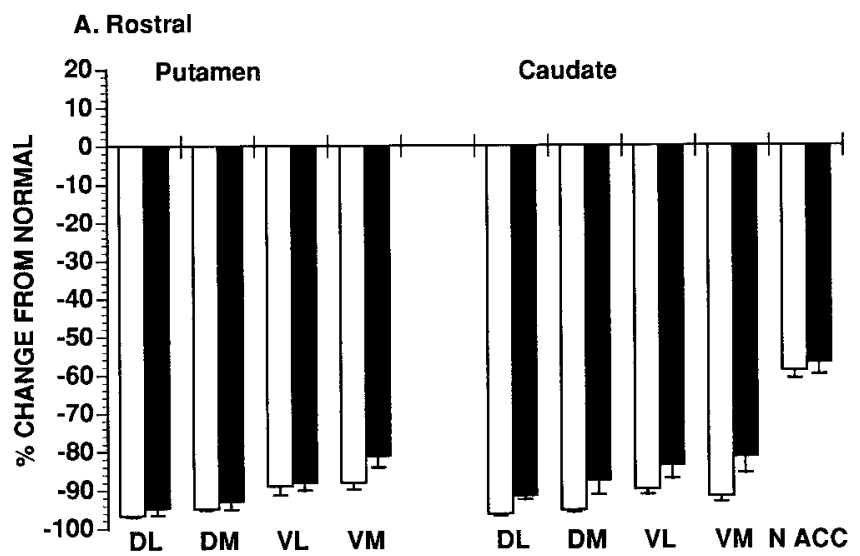

B. Mid

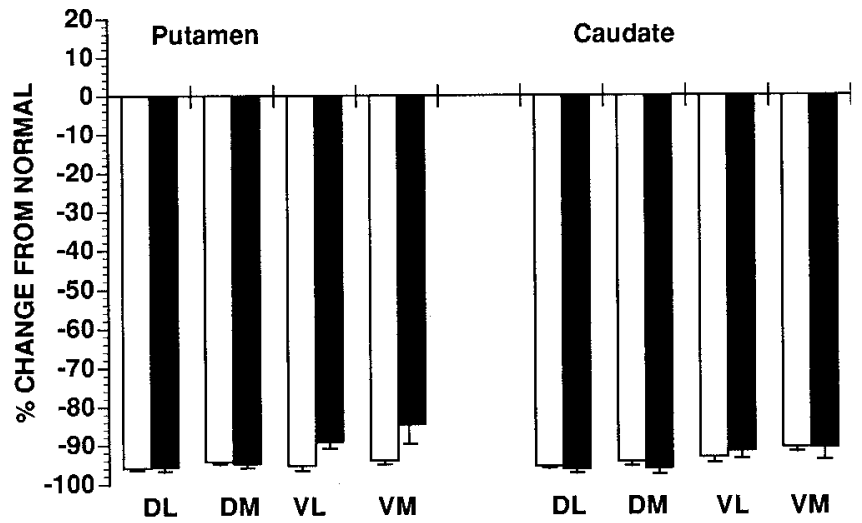

C. Caudal

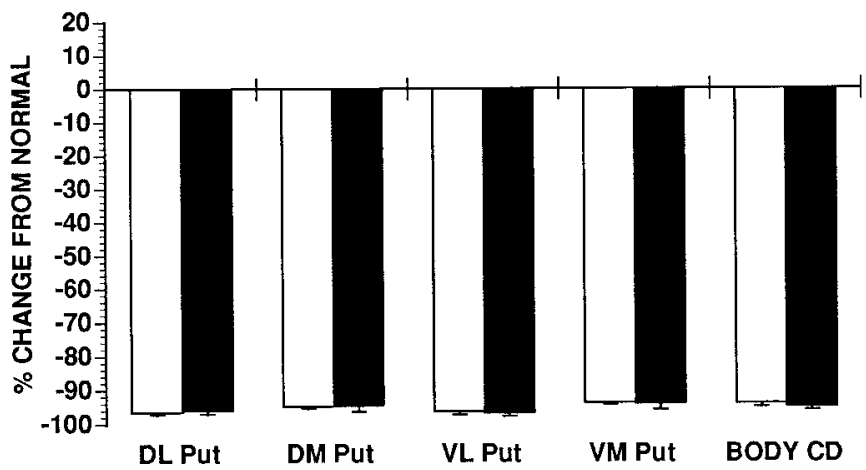

Figure 1. Effect of short-term (acute symptomatic, open bars) and longterm (chronic symptomatic, black-filled bars) MPTP exposure on the concentration of striatal dopamine uptake sites at three different rostrocaudal levels [rostral $(A)$, mid $(B)$, and caudal $(C)$ ]. Results are expressed as the relative percentage difference from the mean of six control monkeys. Both groups of MPTP-treated monkeys had significant loss of specific $\left[{ }^{3} \mathrm{H}\right]$ mazindol binding in all striatal regions at all rostrocaudal levels. However, there were no significant differences in $\left[{ }^{3} \mathrm{H}\right]$ mazindol binding in acute symptomatic versus chronic symptomatic animals. $C D$, Caudate nucleus; $D L$, dorsolateral; $D M$, dorsomedial; $N A C C$, nucleus accumbens; $P u t$, putamen; $V L$, ventrolateral; $V M$, ventromedial.

expression in the ventral putamen $(t=3.48$; $p<0.01$ in the ventrolateral putamen; $t=3.64 ; p<0.01$ in the ventromedial putamen), ventral caudate nucleus $(t=3.50 ; p<0.01$ in the ventrolateral caudate; $t=3.90 ; p<0.01$ in the ventromedial caudate), and nucleus accumbens $(t=4.61 ; p<0.01)$. Levels of PPE gene expression in chronic symptomatic versus acute symp- 


\section{Normal}

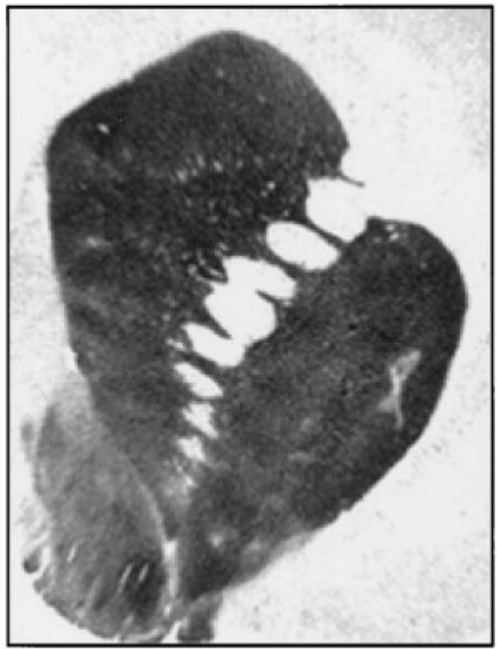

\section{Normal}

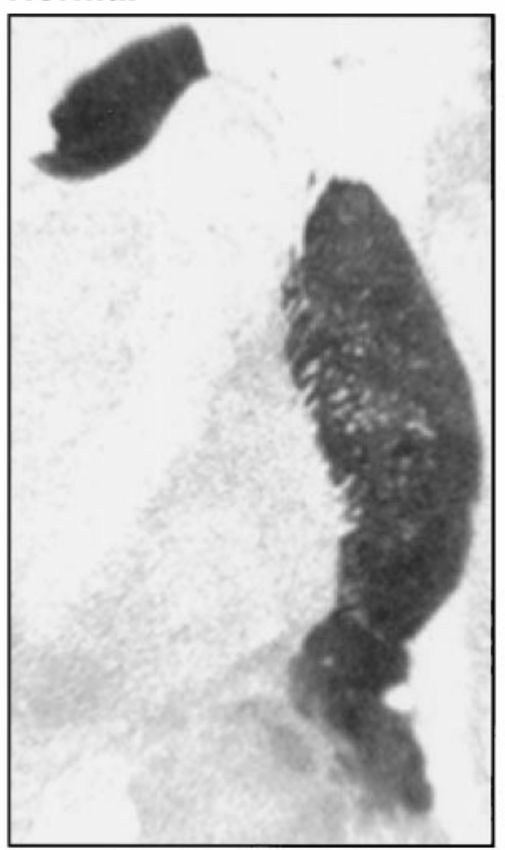

\section{Acute Parkinsonian}

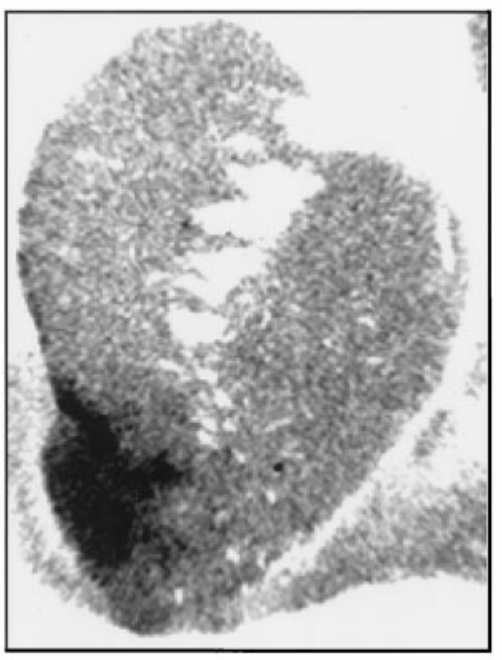

\section{Acute Parkinsonian}

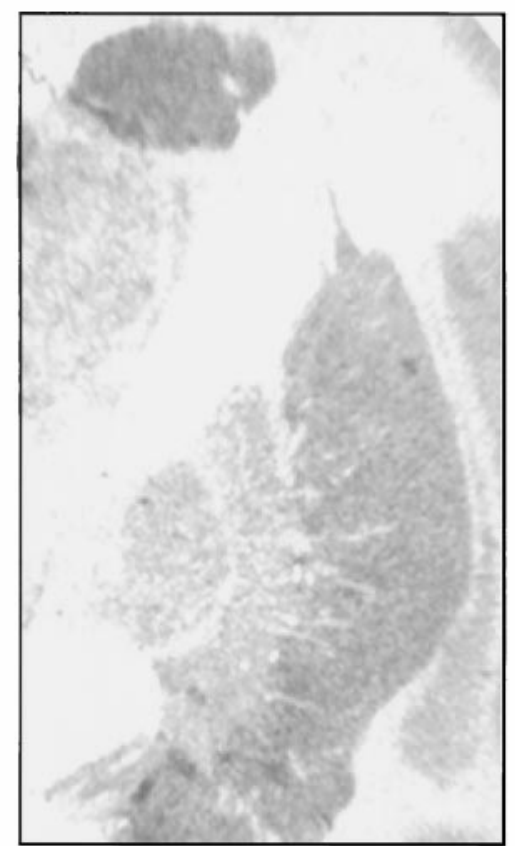

\section{Chronic Parkinsonian}

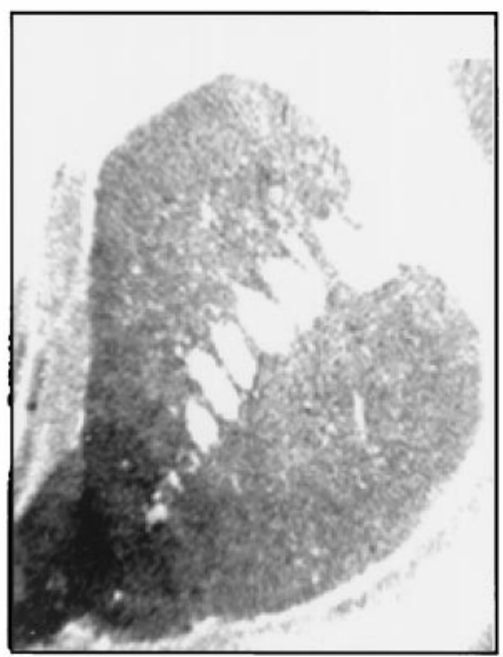

\section{Chronic Parkinsonian}

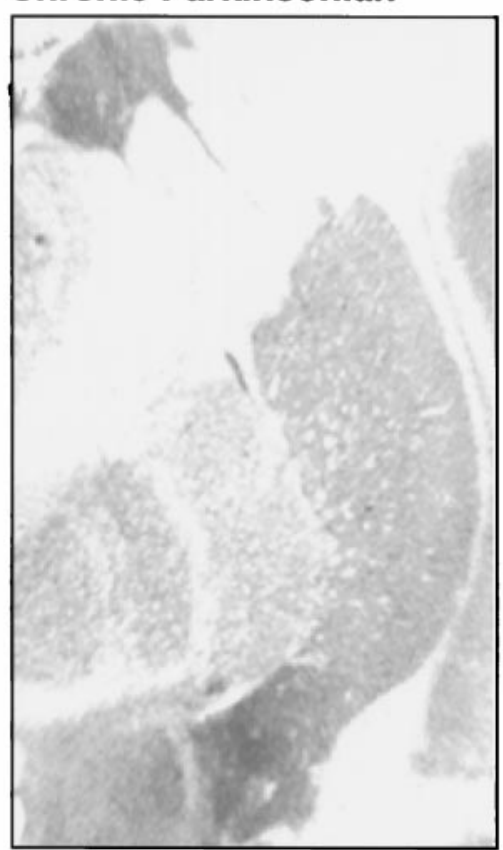

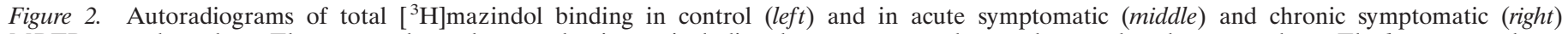

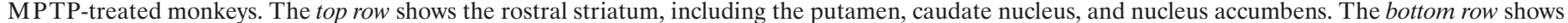

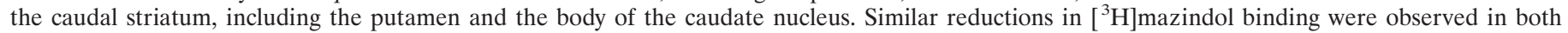
groups of MPTP-treated monkeys.

tomatic animals were significantly different in all striatal subregions at the rostral level (Figs. 3, 4).

At the mid level, PPE mRNA expression in chronic symptomatic animals was significantly increased only in the dorsolateral putamen $(t=3.25 ; p<0.01)$, whereas gene expression at all other striatal subregions was either no different from normal (dorsomedial putamen and dorsolateral and dorsomedial caudate) or significantly decreased from normal $(t=2.08$; $p<0.05$ in the ventrolateral putamen; $t=3.76 ; p<0.01$ in the ventromedial putamen; $t=4.12 ; p<0.01$ in the ventrolateral caudate; $t=2.68$; $p<0.01$ in the ventromedial caudate). Levels of PPE gene expression in chronic symptomatic versus acute symptomatic animals were significantly different $(p<0.05$ to $p<0.01)$ in all striatal subregions (except the dorsomedial caudate nucleus) at the mid level (Fig. 3).

At the caudal level in the chronic symptomatic animals, only PPE gene expression in the ventromedial putamen was significantly different (i.e., decreased) from control values $(t=4.95$; $p<0.01)$. As at the other rostrocaudal levels, differences in PPE expression between acute and chronic symptomatic animals were statistically significant in all striatal subregions $(p<0.01)$ (Figs. 3, 4). In all conditions, control experiments showed that specific hybridization signal was eliminated by competitive inhibition of hybridization by unlabeled antisense PPE probe and by blocking hybridization with unlabeled sense probe (data not shown). 

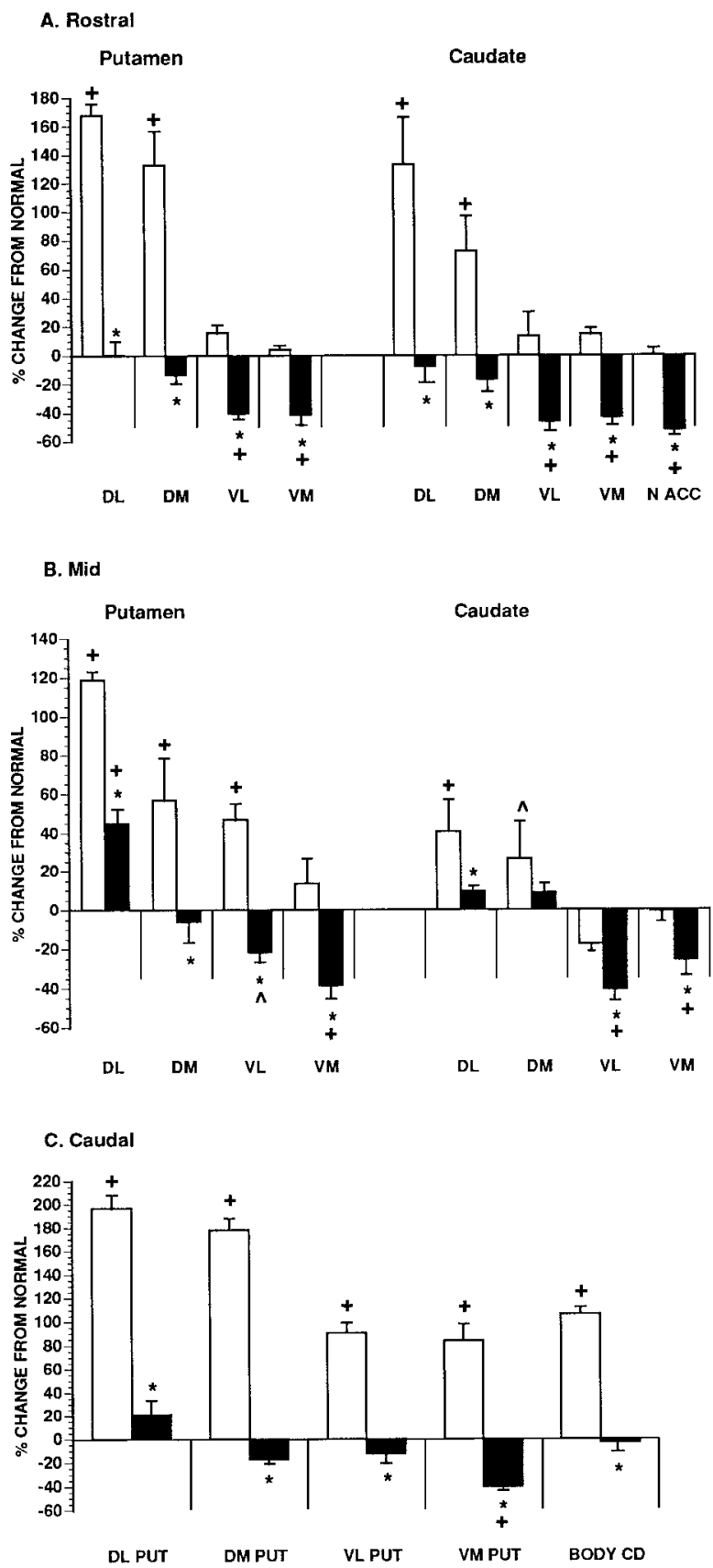

Figure 3. Effect of short-term [acute symptomatic $(n=4)$, open bars] and long-term [chronic symptomatic $(n=6)$, black-filled bars] MPTP exposure on striatal PPE mRNA expression at three different rostrocaudal levels [rostral $(A)$, mid $(B)$, and caudal $(C)]$. Results are expressed as the relative percentage difference from the mean of six control monkeys. Acute symptomatic monkeys had large increases in PPE mRNA expression, particularly in the dorsal striatum at all rostrocaudal levels $(+p<$ 0.01 vs normal controls; $\hat{\wedge} p<0.05$ vs normal controls). In contrast, chronic symptomatic monkeys had comparatively small increases in striatal PPE mRNA expression and in many subregions actually had decreased expression compared with that in control animals $(+p<0.01 \mathrm{vs}$ normal controls; $\hat{p} p<0.05$ vs normal controls). An $*$ denotes a statistically significant difference $(p<0.05)$ versus that in acute symptomatic monkeys. $C D$, Caudate nucleus; $D L$, dorsolateral; $D M$, dorsomedial; $N A C C$, nucleus accumbens; Put, putamen; $V L$, ventrolateral; $V M$, ventromedial.

\section{DISCUSSION}

The results of this study show that monkeys with similar degrees of motor impairment and similar degrees of striatal DA denervation may have drastically different levels of striatal PPE gene expression depending on the duration of the DA denervation. Monkeys with acute parkinsonism had dramatically increased PPE mRNA expression in many striatal regions, whereas PPE mRNA expression was either minimally increased or decreased below normal levels in chronic parkinsonian animals.

Neurochemical changes in the striatum associated with lesions of the nigrostriatal projection and experimentally induced parkinsonism have typically been studied in animals made parkinsonian over a short period of time and killed at short survival times after the injury to the nigrostriatal DA system. Data obtained from these animals have been used in part to develop and support the current functional model of basal ganglia circuitry (Penny and Young, 1983; Albin et al., 1989). In particular, an increase in enkephalin immunostaining and PPE mRNA expression in these DA-lesioned animals has been used to support the notion that DA exerts a tonic inhibitory influence on PPE gene expression. Although data obtained from acute parkinsonian monkeys support the concept that a large decrease in DAergic tone may contribute to upregulation of enkephalin biosynthesis, our data from chronic parkinsonian monkeys suggest that this effect is not maintained despite continued loss of striatal DA. Prolonged DA denervation appears to have the opposite effect of acute DA denervation on enkephalin biosynthesis, causing a downregulation in many striatal regions.

These data suggest that DAergic tone may not be the primary driving force behind regulation of enkephalin biosynthesis in the striatum. Cortical afferents to the striatum have been shown to participate in a complex way in the regulation of striatal neuropeptide expression (Uhl et al., 1988; Kerkerian et al., 1990; Salin and Chesselet, 1992; Campbell and Bjorklund, 1994). In rats, one of the primary influences that maintain increased PPE expression in the DA-denervated striatum is input from the prefrontal cortex (Campbell and Bjorklund, 1994). In acute symptomatic animals, a loss of DA-mediated inhibition of corticostriatal terminals (Garcia-Munoz et al., 1991) could enhance glutamatergic drive on intrinsic striatal neurons and contribute to increased PPE gene expression. If corticostriatal glutamatergic afferents and striatal glutamate levels indeed regulate PPE mRNA expression in primate striatal neurons, then perhaps compensatory changes in corticostriatal excitatory amino acid transmission in chronic parkinsonian animals in part underlie the failure to maintain increased PPE mRNA expression in these animals. However, other factors such as increased intracellular levels of cAMP (Herve et al., 1989) and increased adenosine transmission and activation of adenosine $\mathrm{A} 2$ receptors may also contribute to upregulation of striatal PPE gene expression in the DA-denervated striatum (Schiffmann and Vanderhaeghen, 1993; Campbell and Bjorklund, 1994). Again, compensatory changes in these neurochemical systems in chronic parkinsonian monkeys may contribute to the failure to maintain increased PPE gene expression. The degree to which these various factors play a role in the regulation of PPE mRNA levels in the acutely and chronically DA denervated monkey striatum remains to be studied.

Contrary to a previous report (Herrero et al., 1995), the present results do not confirm that increased striatal PPE gene expression parallels the severity of motor disturbance displayed by MPTP-treated monkeys. Overactive enkephalinergic trans- 


\section{Normal}

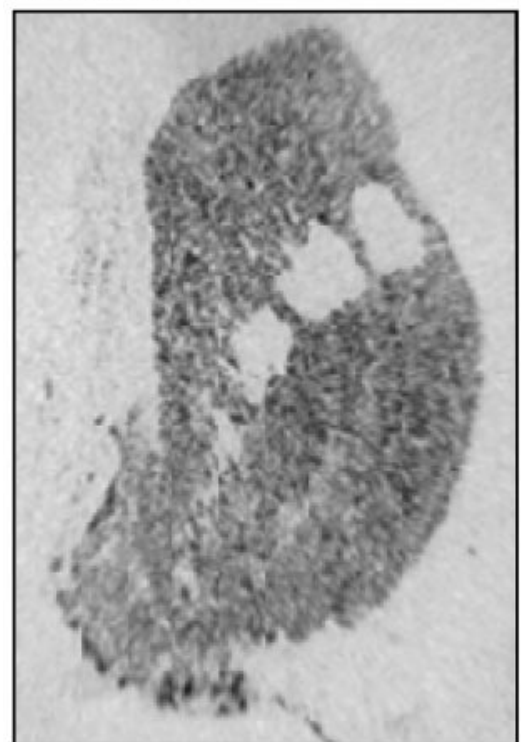

Normal

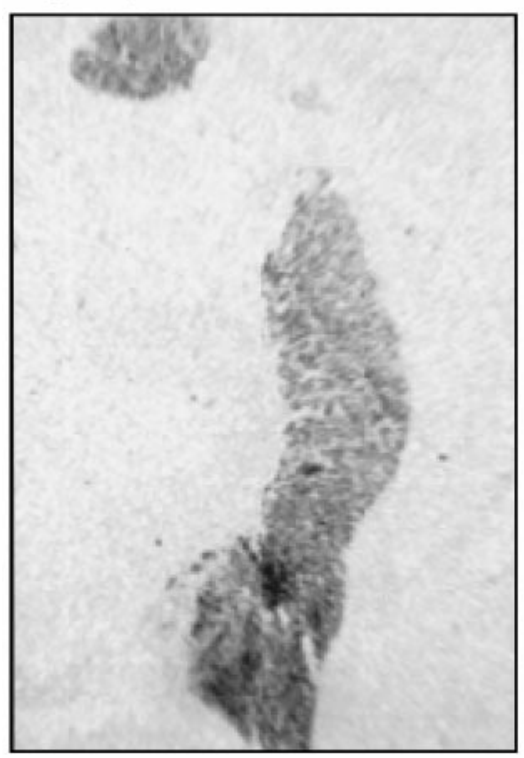

Acute Parkinsonian

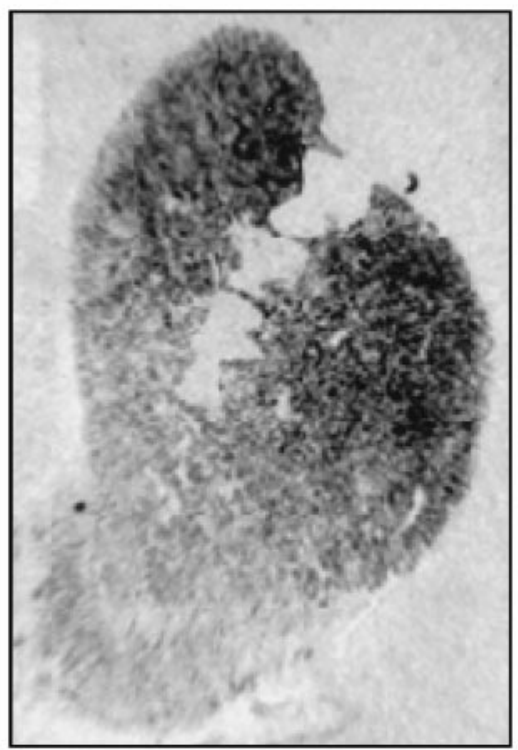

Acute Parkinsonian

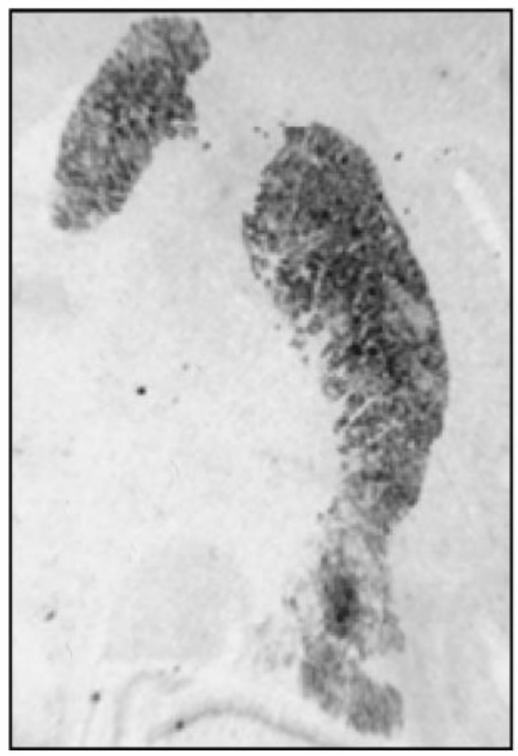

Chronic Parkinsonian

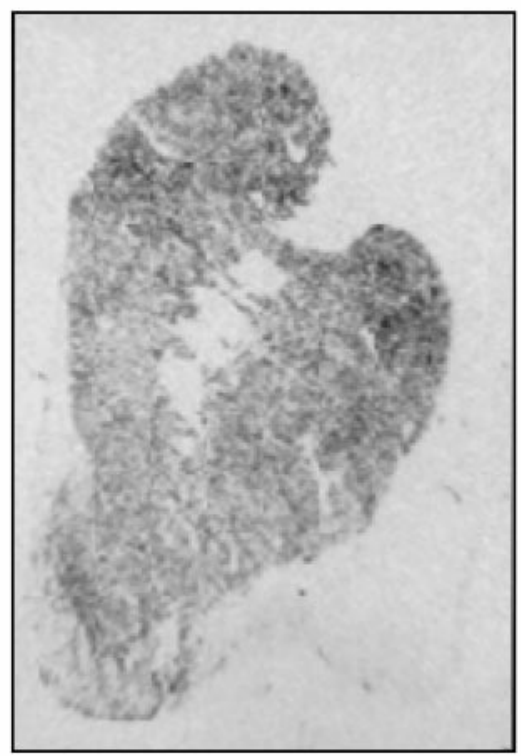

\section{Chronic Parkinsonian}

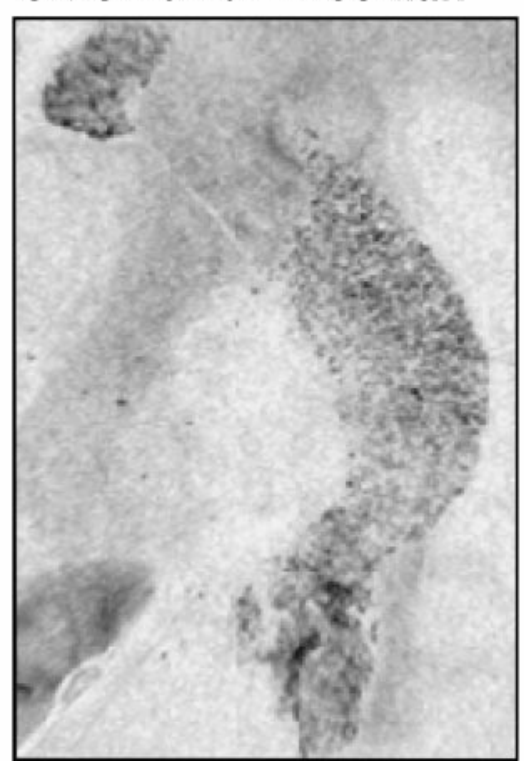

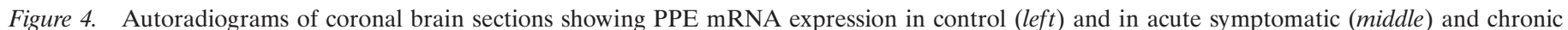

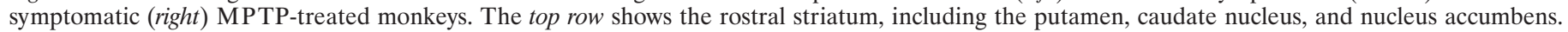

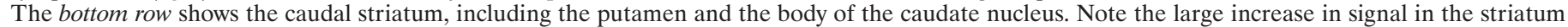
(particularly the dorsolateral striatum) in the acute symptomatic animal that is not seen in the chronic symptomatic animal.

mission seems not to be responsible for the generation of symptoms. This has also been suggested to be the case in reserpinized rats (Maneuf et al., 1994) and in MPTP-treated mice (Gudehithlu et al., 1991). Also, the present findings question the functional significance of upregulated GABA/enkephalin transmission in the indirect striatopallidal pathway hypothesized to occur in the current model of basal ganglia functional circuitry in parkinsonism. The extent to which GABA neurotransmission is upregulated in the indirect striatopallidal circuit in chronic symptomatic parkinsonian monkeys is unknown. However, GAD65 and GAD67 mRNA levels were increased in the dorsolateral putamen in acute parkinsonian monkeys (Soghomonian and Laprade, 1997). In these animals, GAD mRNA levels were in- creased in PPE-labeled (presumably striatopallidal) neurons but not in PPE-unlabeled neurons. If PPE and GAD gene expression is coregulated in striatal neurons, then one might expect that there is not a significant upregulation of striatopallidal GABAergic neurotransmission in chronic parkinsonian monkeys. Alternatively, GAD and PPE mRNAs may be differentially regulated in the chronically DA-denervated primate striatum, as has been observed in DA-denervated neonatal rats (Soghomonian, 1994). This could result in overactivity of striatopallidal GABAergic transmission without concomitant upregulation of enkephalinergic transmission.

It is also possible that increased enkephalinergic transmission in striatopallidal neurons is involved in regulatory processes not 
directly related to generation of parkinsonian symptoms. Maneuf et al. (1994) have suggested that increased enkephalinergic transmission in the striatopallidal circuit could represent an endogenous mechanism attempting to reduce an overactive inhibitory GABAergic input from the striatum. This potential compensatory mechanism may fail in chronic parkinsonian animals. It may also be that the indirect striatopallidal circuit may either not be critically involved in Parkinson symptom generation, as suggested in recent reevaluations of the current model of basal ganglia functional circuitry (Chesselet and Delfs, 1996; Parent and Cicchetti, 1998), or else the role of striatal enkephalin in producing changes in the physiology of the external globus pallidus (and subsequently the subthalamic nucleus) may need to be reevaluated. However, because neurosurgical approaches to PD that rely on altering the function of the internal globus pallidus (GP) or subthalamic nucleus are at least partially efficacious, the suggestion is that increased activity in the internal GP, and perhaps also the subthalamic nucleus, may play important roles in the expression of parkinsonian symptoms. Further study of the differences in basal ganglia physiology between acute and chronic parkinsonian monkeys is needed to better understand the functioning of direct and indirect striatopallidal output pathways and the complex neural processes underlying symptom generation in parkinsonism.

\section{REFERENCES}

Albin RL, Young AB, Penny JB (1989) The functional anatomy of basal ganglia disorders. Trends Neurosci 12:366-375.

Asselin M-C, Soghomonian J-J, Cote P-Y, Parent A (1994) Striatal changes in preproenkephalin mRNA levels in parkinsonian monkeys. NeuroReport 5:2137-2140.

Augood SJ, Emson PC, Mitchell IJ, Boyce S, Clarke CE, Crossman AR (1989) Cellular localization of enkephalin gene expression in MPTPtreated cynomolgus monkeys. Mol Brain Res 6:85-92.

Campbell K, Bjorklund A (1994) Prefrontal corticostriatal afferents maintain increased enkephalin gene expression in the dopaminedenervated rat striatum. Eur J Neurosci 6:1371-1383.

Chesselet M-F, Delfs JM (1996) Basal ganglia and movement disorders: an update. Trends Neurosci 19:417-421.

Fernandez A, de Ceballos ML, Jenner P, Marsden CD (1992) Striatal neuropeptide levels in Parkinson's disease patients. Neurosci Lett 145:171-174.

Garcia-Munoz M, Young SJ, Groves PM (1991) Terminal excitability of the corticostriatal pathway. I. Regulation by dopamine receptor stimulation. Brain Res 551:195-206.

Gerfen CR, Engber TM, Mahan LC, Susel Z, Chase TN, Monsma FJ, Sibley DR (1990) D-1 and D-2 dopamine receptor-regulated gene expression of striatonigral and striatopallidal neurons. Science 250:1429-1432.

Gudehithlu KP, Duchemin AM, Tejwani GA, Neff NH, Hadjiconstantinou M (1991) Preproenkephalin mRNA and methionineenkephalin increase in mouse striatum after 1-methyl-4-phenyl-1,2,3,6tetrahydropyridine treatment. J Neurochem 56:1043-1048.

Herrero M-T, Augood SJ, Hirsch EC, Javoy-Agid F, Luquin MR, Agid Y, Obeso JA, Emson PC (1995) Effects of L-dopa on preproenkephalin and preprotachykinin gene expression in the MPTP-treated monkey striatum. Neuroscience 68:1189-1198.

Herve D, Trovero F, Blanc G, Thierry AM, Glowinski J, Tassin JP (1989) Nondopaminergic prefrontocortical efferent fibers modulate D1 receptor denervation supersensitivity in specific regions of the rat striatum. J Neurosci 9:3699-3708.

Kerkerian L, Salin P, Nieoullon A (1990) Cortical regulation of striatal neuropeptide Y (NPY)-containing neurons in the rat. Putative modu- latory influence on striatal dopamine-NPY relationships. Eur J Neurosci 2:181-189.

Levy R, Vila M, Herrero M-T, Faucheux B, Agid Y, Hirsch EC (1995) Striatal expression of substance $\mathrm{P}$ and methionin-enkephalin genes in patients with Parkinson's disease. Neurosci Lett 199:220-224.

Llorens-Cortes C, Javoy-Agid F, Agid Y, Taquet H, Schwartz JC (1984) Enkephalinergic markers in substantia nigra and caudate nucleus from parkinsonian subjects. J Neurochem 43:874-877.

Maneuf YP, Mitchell IJ, Crossman AR, Brotchie JM (1994) On the role of enkephalin cotransmission in the GABAergic striatal efferents to the globus pallidus. Exp Neurol 125:65-71.

Nisbet AP, Foster OJF, Kingsbury A, Eve DJ, Daniel SE, Marsden CD, Lees AJ (1995) Preproenkephalin and preprotachykinin messenger RNA expression in normal human basal ganglia and in Parkinson's disease. Neuroscience 66:361-376.

Normand E, Popovici T, Onteniente B, Fellman D, Pieter-Tonneau D, Auffrey C, Bloch B (1988) Dopaminergic neurons of the substantia nigra modulate preproenkephalin A gene expression in rat striatal neurons. Brain Res 439:39-46.

Parent A, Cicchetti F (1998) The current model of basal ganglia organization under scrutiny. Mov Disord 13:199-202.

Penny JB, Young AB (1983) Speculation on the functional anatomy of basal ganglia disorders. Annu Rev Neurosc 6:73-94.

Rioux L, Frohna PA, Joyce JN, Schneider JS (1997) The effects of chronic levodopa treatment on pre- and postsynaptic markers of dopaminergic function in striatum of parkinsonian monkeys. Mov Disord 12:148-158.

Robertson RG, Clark CE, Boyce S, Sambrook MA, Crossman AR (1990) The role of striatopallidal neurons utilizing GABA in the pathophysiology of MPTP-induced parkinsonism. Brain Res 531:95-104.

Salin P, Chesselet M-F (1992) Paradoxical increases in striatal neuropeptide gene expression following ischemic lesions of the cerebral cortex. Proc Natl Acad Sci USA 89:9954-9958.

Schiffmann SN, Vanderhaeghen J-J (1993) Adenosine A2 receptors regulate the gene expression of striatopallidal and striatonigral neurons. J Neurosci 13:1080-1087.

Schneider JS, Pope-Coleman A, Van Velson M, Menzaghi F, Lloyd GK (1998) Effects of SIB-1508Y, a novel neuronal nicotinic acetylcholine receptor agonist, on motor behavior in parkinsonian monkeys. Mov Disord 13:637-642.

Sivam SP (1991) Dopamine dependent decrease in enkephalin and substance $\mathrm{P}$ levels in basal ganglia regions of postmortem parkinsonian brains. Neuropeptides 18:201-207.

Sivam SP, Krause JE (1990) The adaptation of enkephalin, tachykinin and monoamine neurons of the basal ganglia following neonatal dopaminergic denervation is dependent on the extent of dopamine depletion. Brain Res 536:169-175.

Soghomonian J-J (1994) Differential regulation of glutamate decarboxylase and preproenkephalin mRNA levels in the rat striatum. Brain Res 640:146-154.

Soghomonian J-J, Laprade N (1997) Glutamate decarboxylase (GAD67 and GAD65) gene expression is increased in a subpopulation of neurons in the putamen of parkinsonian monkeys. Synapse 27:122-132.

Taquet H, Javoy-Agid F, Hamon M, Legrande JC, Agid Y, Cesselin F (1983) Parkinson's disease affects differently met $^{5}$ - and leu ${ }^{5}$ enkephalin in the human brain. Brain Res 280:379-382.

Uhl GR, Bradford N, Douglas J (1988) Differential expression of preproenkephalin and preprodynorphin mRNAs in striatal neurons: high levels of preproenkephalin expression depend on cerebral cortical afferents. J Neurosci 8:4755-4764.

Voorn P, Roest G, Groenewegen HJ (1987) Increase of enkephalin and decrease of substance $\mathrm{P}$ immunoreactivity in the dorsal and ventral striatum of the rat after midbrain 6-hydroxydopamine lesions. Brain Res 412:391-396.

Young III WS, Bonner TI, Brann MR (1986) Mesencephalic dopaminergic neurons regulate the expression of neuropeptide mRNAs in the rat forebrain. Proc Natl Acad Sci USA 83:9827-9831. 